\title{
Brachypterous Stenus species (Coleoptera, Staphylinidae, Steninae) from West-Central China
}

\author{
Liang Tang, Yun-Long Zhao \& Volker Puthz
}

Tang, L., Zhao, Y.-L. \& Puthz, V. 2009: Brachypterous Stenus species (Coleoptera, Staphylinidae, Steninae) from West-Central China. — Entomol. Fennica 20: 191-199.

Five new brachypterous species belonging to the genus Stenus Latreille are described from Taibaishan Nature Reserve, Shaanxi Prov., West-Central China: $S$. (Hypostenus) hui Tang \& Puthz sp. n., S. (Hemistenus) alioventralis Tang \& Puthz sp. n., S. (Hemistenus) fortunatoris Tang \& Puthz sp. n., S. (Hemistenus) taibaishanus Tang \& Puthz sp. n. and S. (Hypostenus) nigriceps Tang \& Puthz sp. n.

L. Tang* \& Y.-L. Zhao, Department of Biology, East China Normal University, Shanghai, 3663 North Zhongshan Road, Shanghai, 200062 P. R. China; *Present address: Department of Biology, Shanghai Normal University, 100 Guilin Road, Building 1-323, Shanghai, 200234 P. R. China; E-mail: monkey_zzz1980@163.com

V. Puthz, c/o Limnologische Fluss-Station, MPI-Limnologie, Damenweg 1, D36110 Schlitz, Germany

Received 15 July 2006, accepted 6 October 2008

\section{Introduction}

Stenus Latreille (Latreille 1797) includes presently more than 2,300 species. Among them, the brachypterous species are of special interest, as most of them are endemic to small areas and with low dispersal potential. They usually live at higher altitudes and are equally diverse as their winged relatives at lower altitudes. The most effective way to capture brachypterous Stenus is by sifting leaf litter.

In summer 2004, Mr. J.-Y. Hu and the first author made an insect-collecting trip to Taibaishan Nature Reserve, Shaanxi Prov., West-Central China. They obtained brachypterous Stenus specimens, which after careful examination were recognized as belonging to five species, all of them new to science. Two brachypterous Stenus species were previously known from this area, i.e. $S$. nigritus Tang \& Li, 2005 and S. conseminiger Zhao \& Zhou, 2006. In the present paper we describe five new species including material from other collectors (available for this study for the third author). This study also includes some specimens collected from Foping National Reserve, which is adjacent to Taibaishan Nature Reserve.

\section{Material and methods}

The insects studied in this paper were collected mainly by shifting leaf litters in broad leaf forests from Shaanxi Province, west-central China.

For examining the aedeagus, the last two abdominal segments were removed after softening in hot water and the separated aedeagus was mounted in Euparal (Chroma Geselschaft Schmidt, Koengen, Germany) on plastic slides. 
The drawings were made under the stereoscope SZ40 and the microscope Olympus CX21 and the photos were taken with Olympus C-5050 camera through Olympus SZX12 microscope.

\section{Descriptions}

\subsection{Stenus (Hypostenus) hui, Tang \& Puthz sp. n. (Figs. 1 a, 2 a, 3 a-c)}

Type specimens. Holotype: male, Taibai Shan above Houzhenzi, 1,300-1,700 m a.s.1., 9.VI.3.VII.1998, P. Jäger and J. Martens leg. Paratypes: 1 male, Foping Nature Reserve, Shaanxi Prov., alt. 2,065 m, 19.VII.2004, J.-Y. Hu and L. Tang leg.;1 female, Foping Nature Reserve, Shaanxi Prov., alt. 1,400-1,800 m, 19.VII.2004, J.-Y. Hu and L. Tang leg.; 1 female, Taibaishan Nature Reserve, Shaanxi Prov., alt. 2,350-2,750 m, 14.VII.2004, J.-Y. Hu and L. Tang leg.; 1 male, river bank above Houzhenzi, $115 \mathrm{~km}$ WSW X'ian, 1,450 m a.s.1., $33.50 \mathrm{~N}, 107.47 \mathrm{E}$, gravel bank (floating), mixed deciduous forest, moss, mushrooms sifted, 5.VII.2001, M. Schülke leg. (C01-06); 2 males, Quinling Shan, N-slope, pass road Zhouzi-Foping $106 \mathrm{~km}$ SW Xi'an,1,990 m a.s.1., 33.44N, 107.59E, 2.VII.2001, A. Smetana leg. (cSmetana, cPuthz); 1 male, 4 females, China: Shaanxi Prov., Zhouzhi County, Qinling Daoban, $38^{\circ} 43.645^{\prime} \mathrm{N}, 1^{\circ} 7^{\circ} 58.147^{\prime} \mathrm{E}$, alt. 1,900m, 4.V.2008, H. Huang and W. Xu leg.; 2 males, 1 female, China: Shaanxi Prov., Zhouzhi County, Houzhenzi, Qinling West Sangongli Gou, $33^{\circ} 50.613^{\prime}$ N, $107^{\circ} 48.524^{\prime}$ E, alt. 1,336 m, 17.-19.V.2008, H. Huang and W. Xu leg.; 7 males, 10 females, China: Shaanxi Prov., Mei County, Taibai-Shan, Kaitianguan, $34^{\circ} 00.692^{\prime}$ N, $107^{\circ} 51.415^{\prime}$ E, alt. 1,883 m, 22.-23.V.2008, H. Huang and W. Xu leg.

Holotype is deposited in the Staatliches Museum für Naturkunde, Stuttgart, paratypes in coll. Schülke (Berlin), in coll. Puthz (Schlitz), and in the Department of Biology, Shanghai Normal University.

Description. Brachypterous, blackish brown, slightly shiny, head and abdomen coarsely and very densely, pronotum and elytra coarsely and rugosely punctate; pubescence short, recumbent. Antennae yellowish, club infuscate. Maxillary palpi yellowish. Legs light brown. Clypeus blackish, labrum dark brown, densely pubescent. Paraglossae oval.

Length: 3.8-4.7 mm (forebody: 2.1-2.2 mm).

Head 1.12 times as wide as elytra, 1.46 times as wide as long; clypeofrontal area densely punctate and pubescent; basiantennal tubercles small; interocular area with deep longitudinal furrows, median portion convex, slightly extending beyond the level of inner eye margins; punctures round, partly rugose and confluent, larger and slightly sparser on median area than those near inner margins of eyes, diameter of a large puncture about as wide as basal cross section of $2^{\text {nd }}$ antennal segment, interstices much smaller than half diameter of punctures. Antennae when reflexed slightly extending beyond the posterior margin of pronotum; $3^{\text {rd }}$ to $8^{\text {th }}$ segments much narrower than $2^{\text {nd }} ; 9^{\text {th }}$ to $11^{\text {th }}$ gradually broadened, forming a loose club; the relative length of segments from base to apex as $6.0: 4.5: 10.0: 6.5: 5.5$ : 4.5: $5.0: 3.5: 3.5: 4.0: 4.5$.

Pronotum 1.14 times as long as wide, 0.82 times as wide as elytra, widest near the middle and constricted at base; disk uneven, with a deep median longitudinal furrow, two impressions in anterior half, a transverse impression in about middle and two impressions in posterior half; punctures very rugose and confluent, a little larger than those on head, interstices much smaller than half diameter of punctures.

Elytra as long as wide, distinctly constricted at base, lateral margins gently divergent posteriad; posterior conjoint margins roundly and distinctly emarginate at the middle; disk uneven with a deep humeral impression, a distinct postero-lateral impression and a long and deep sutural impression, median portion between humeral impression and sutural impression strongly convex; punctures very rugose and confluent, larger than those on the pronotum, interstices densely sculptured, much smaller than half diameter of punctures.

Abdomen cylindrical; distinct paratergites absent, but rudimentary lateral border present, segments distinctly split at about posterior sixth; a distinct membranous fringe at apical margin of tergite 7; punctures round to elliptic, gradually becoming smaller posteriad, interstices smaller than half diameter of punctures, faintly reticulated on last tergites. 
Fig. 1. Adult habitus. - a. Stenus (Hypostenus) hui sp. n., female. - b. S. (Hypostenus) alioventralis sp. n., female. - c. S. (Hemistenus) fortunatoris sp. n., female. - d. S. (Hemistenus) taibaishanus sp. n., male. - e. S. (Hypostenus) nigriceps sp. n., male.
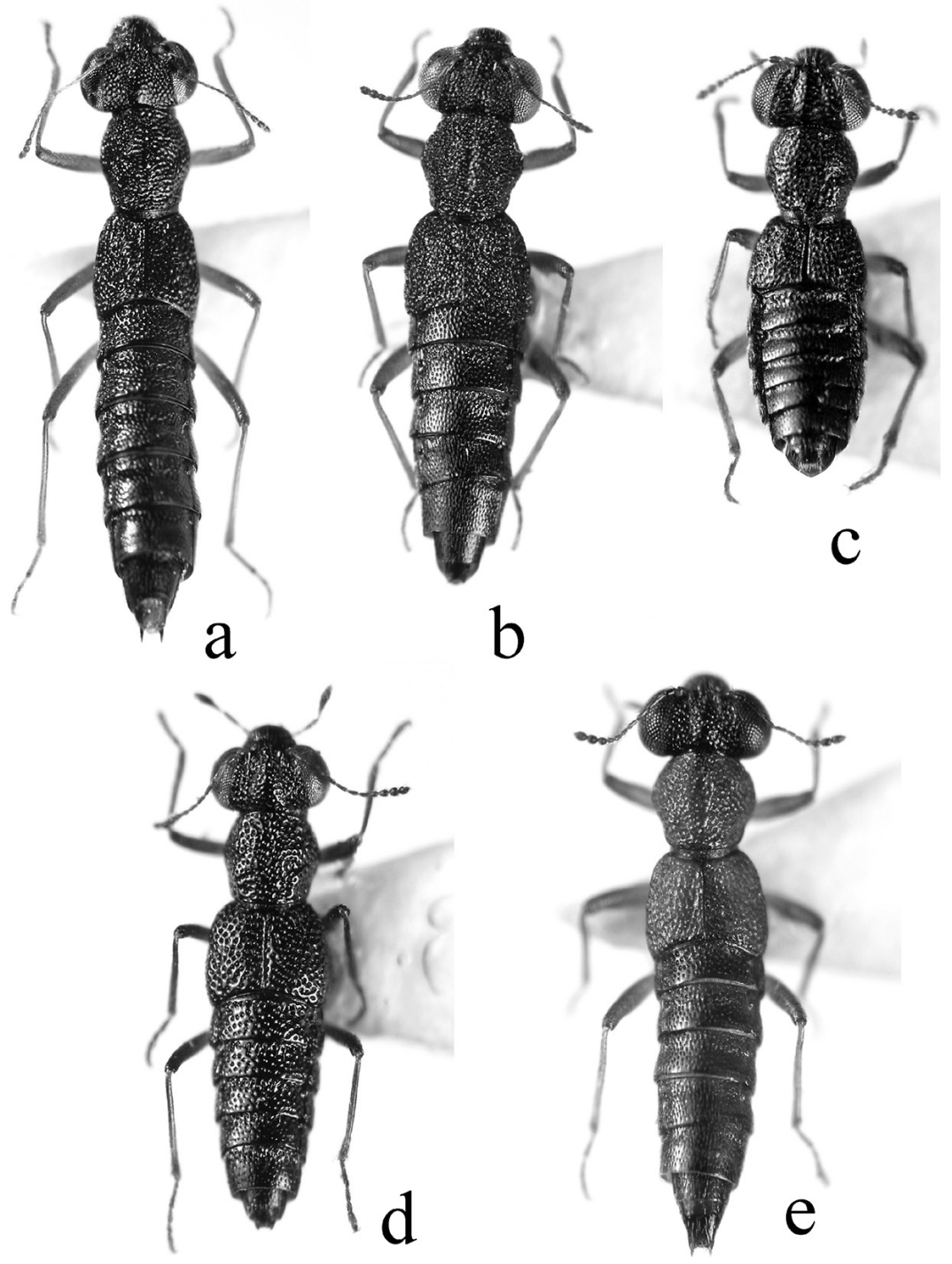

Legs elongate, hind tarsi 0.71 times as long as hind tibiae, $4^{\text {th }}$ tarsomeres strongly bilobed.

Male. Seventh sternite with a slight emargination at the middle of posterior margin; $8^{\text {th }}$ sternite (Fig. 3 a) with a triangular emargination at the middle of posterior margin; $9^{\text {th }}$ sternite (Fig. 3 b) with very long apicolateral projections, posterior margin serrate. Aedeagus (Fig. 2 a) with median lobe broadened in anterior third, anterior margin with numerous setae, acutely pointed medially; expulsion hooks strong, connected proximately by a transverse dorsal clasp, internal sac as in the figure; parameres slightly longer than the median lobe, narrowed at apex, with 12-15 strong subapical setae.

Female. Abdomen broader than that in male; $8^{\text {th }}$ sternite entire; strongly sclerotiized spermatheca as in Fig. 3 c.

Distribution. China (Shaanxi Prov.).

Remarks. This new species belongs to the Stenus (Hypostenus) indubius Sharp group (Naomi 2006) and resembles S. sawadai Hromádka, but may be distinguished easily by the much coarser abdominal punctation and the sexual characters. A similar undescribed species, which will be described next, lives in Daba Shan, Shaanxi. 
Etymology. This species is named in honor of Mr. J.-Y. Hu, who collected some Stenus specimens used in this study and helped us in many other ways during this study.

\subsection{Stenus (Hemistenus) alioventralis, Tang \& Puthz sp. n. (Figs. 1 b, 2 b, 3 e-h)}

Type specimens. Holotype: male, Taibaishan Nature Reserve, Shaanxi Prov., alt. 2,350-2,750 m, 15.VII.2004, J.-Y. Hu and L. Tang leg. Paratype: 2 females, same data as for the holotype; 1 female, China: S Shaanxi Qinling Shan mt., range $\mathrm{W}$ pass on rd. Xi'an-Shagoujie, $45 \mathrm{~km}$ SSW Xi'an, 33 $52^{\prime} \mathrm{N} 1^{\prime} 108^{\circ} 46^{\prime} \mathrm{E}, 2,600 \mathrm{~m}$ a.s.l., 25.VII.2001, A. Smetana [C118]; 3 males, 3 females, China: Shaanxi Prov., Mei County, TaibaiShan, Kaitianguan, $34^{\circ} 00.692^{\prime} \mathrm{N}, 107^{\circ} 51.415^{\prime} \mathrm{E}$, alt. 1,883 m, 22.-23.V.2008, H. Huang and W. Xu leg.

Holotype and paratype are deposited in the Department of Biology, Shanghai Normal University; paratypes also in coll. Puthz (Schlitz) and coll. Smetana (Ottawa).

Description. Brachypterous, black with a slight brownish hue, almost dull, very coarsely and extremely densely punctate, sculpture rugose on pronotum and elytra; pubescence very short, recumbent. Antennae brownish. Maxillary palpi light brown. Legs reddish brown. Clypeus black, labrum dark brown, moderately densely pubescent. Paraglossae oval.

Length: 3.9-3.9 mm (forebody: $1.7-1.8 \mathrm{~mm}$ ).

Head as wide as elytra, 1.52 times as wide as long; clypeofrontal area densely punctate and pubescent; basiantennal tubercles small; interocular area with deep longitudinal furrows, median area convex, extending beyond the level of inner eye margins; punctures round and very dense, those on median area a little larger than those near inner margins of eyes, diameter of a large puncture about as wide as medial cross section of $2^{\text {nd }}$ antennal segment, interstices between punctures smooth, much smaller than half diameter of punctures. Antennae short, reaching about $1 / 5$ at base of pronotum when reflexed; $3^{\text {rd }}$ to $7^{\text {th }}$ segments much narrower than $2^{\text {nd }} ; 8^{\text {th }}$ to $11^{\text {th }}$ gradually broadened, forming a loose club; the relative length of segments from base to apex as 3.0: 3.5 : $4.5: 3.5: 3.5: 2.5: 2.5: 2.0: 2.5: 2.5: 3.5$.

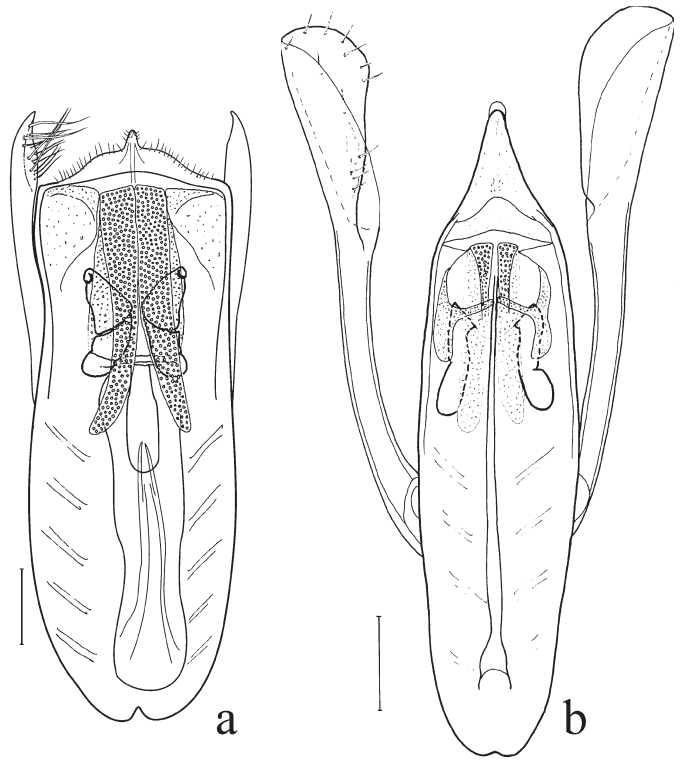

Fig. 2. - a. Aedeagus of Stenus (Hypostenus) hui sp. $\mathrm{n}$. - b. Aedeagus of $S$. (Hemistenus) alioventralis sp. n. Ventral views. Scale $=0.1 \mathrm{~mm}$.

Pronotum 1.04 times as long as wide, 0.81 times as wide as elytra, sides strongly convex, widest slightly before the middle and constricted at base; disk uneven, with a deep median longitudinal furrow and longitudinal impressions laterally of the median furrow, punctation coarse, very dense, rugose, punctures slightly smaller than those on head, interstices shallowly sculptured, nearly smooth, much smaller than half diameter of punctures.

Elytra 0.84 times as long as wide, distinctly constricted at base, lateral margins gently divergent posteriad, with a very slight concavity in posterior half; posterior conjoint margins roundly and shallowly emarginate at the middle; humeral impression distinct, a postero-lateral impression less distinct, sutural impression long and deep; punctation rugose and shortly confluent longitudinally, slightly coarser than on head, interstices shallowly sculptured, nearly smooth, much smaller than half diameter of punctures. Hind wings degenerate.

Abdomen elliptical, paratergites present only in $3^{\text {rd }}$ segment, segments 4-6 line-like margined; no membranous fringe at apical margin of tergite 7; the whole abdomen coarsely (anteriorly) to moderately coarsely (posteriorly) and extremely 
Fig. 3. Stenus (Hypostenus) hui sp. n. (a-c). - a. Male $8^{\text {th }}$ sternite.

- b. Male $9^{\text {th }}$ sternite.

- c. Spermatheca. - d. Spermatheca of Stenus (Hemistenus) fortunatoris sp. n. Stenus (Hemistenus) alioventralis sp. n. (e-h). - e. Male $3^{\text {rd }}$ to $7^{\text {th }}$ sternites. $-\mathrm{f}$. Male $8^{\text {th }}$ sternite. - g. Male $9^{\text {th }}$ sternite.

- h. Spermatheca.

Scale $=0.25 \mathrm{~mm}$.
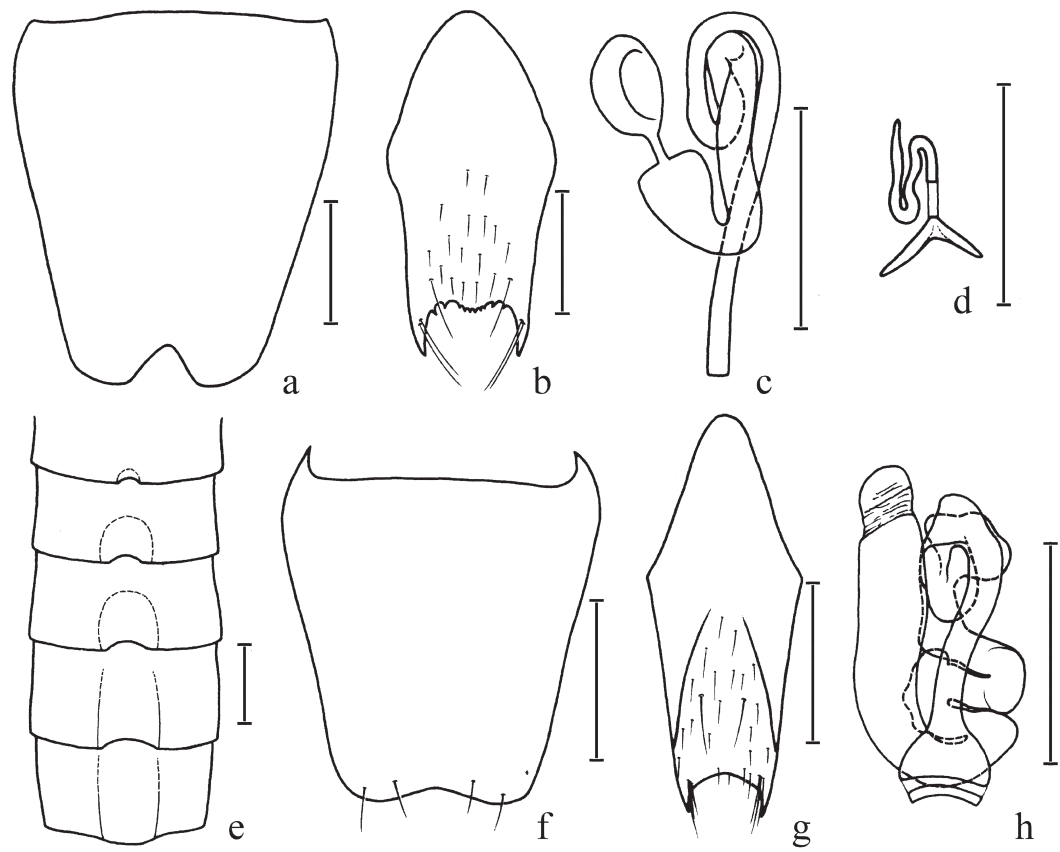

g

$\mathrm{h}$ densely punctate, interstices smaller than half diameter of punctures, shallowly microsculptured on the last tergites.

Legs relatively short, hind tarsi 0.65 times as long as hind tibiae, $4^{\text {th }}$ tarsomeres strongly bilobed.

Male. Mesotibiae and metatibiae each with a tooth on inner side of apex; $3^{\text {rd }}$ to $5^{\text {th }}$ sternite (Fig. 3 e) flat at posteromedian part with a shallow emargination along the posterior margin of the flat; $6^{\text {th }}$ sternite (Fig. 3 e) impressed posterio-medially with a shallow emargination along the posterior margin of the impression; $7^{\text {th }}$ sternite (Fig. 3 e) impressed at posteromedian part with a short, wide projection along the posterior margin of the impression; $8^{\text {th }}$ sternite (Fig. $3 \mathrm{f}$ ) with a weak emargination at the middle of posterior margin; $9^{\text {th }}$ sternite (Fig. $3 \mathrm{~g}$ ) with a pair of posterolateral projections which are acutely pointed apicad, posterior margin smoothly emarginated. Aedeagus (Fig. 2 b), median lobe triangularly narrowed into a moderately narrow membranous apex, apical portion with a slight longitudinal keel ventrally, expulsion clasp strongly sclerotized; parameres extending beyond apex of median lobe, broadened and folded at apex, with about 20-24 setae on apico-internal margins.

Female. Abdomen broader than that in male; $8^{\text {th }}$ sternite with posterior margin widely pointed at middle; sclerotized spermatheca as in Fig. $3 \mathrm{~h}$.

Distribution. China (Shaanxi Prov.).

Remarks. This new species has some affinities to the Nepalese $S$. evexifrons Puthz. It can be distinguished from other species by the combination of the following characters: 1. blackish body; 2. punctures on pronotum and elytra rugose and confluent; 3 . whole abdomen coarsely and very densely punctate, 4 . mesotibiae and metatibiae of male each with a tooth on inner side of apex; 5 . apical sclerotized area of aedeagus with a cuspidate projection at apex and a median longitudinal keel at apical half, parameres of aedeagus broadened and folded at apex.

Etymology. The specific name is a combination of the Latin words "alio" and "ventralis" after its sternites which are well decorated by second sexual characters.

\subsection{Stenus (Hemistenus) fortunatoris, Tang \& Puthz sp. n. (Figs. 1 c, 3 d)}

Type specimens. Holotype: female, Taibaishan Nature Reserve, Shaanxi Prov., alt. 2,750 m, 14.VII.2004, J.-Y. Hu and L. Tang leg.

The type specimen is deposited in the Depart- 
ment of Biology, Shanghai Normal University.

Description. Apterous, black, slightly shiny, forebody moderately coarsely, densely punctate, abdomen finely and densely (anteriorly) to very finely and moderately densely (posteriorly) punctate; pubescence short, recumbent. Antennae brown. First two segments of maxillary palpi yellowish, $3^{\text {rd }}$ segment infuscate. Legs reddish yellow. Clypeus black, labrunm dark brown, pubescence moderately sparse. Paraglossae oval.

Length: $2.0 \mathrm{~mm}$, (range of presumed species length: 1.8-2.4 mm, forebody: $1.1 \mathrm{~mm}$ ).

Head slightly broader than elytra, 1.43 times as wide as long; clypeofrontal area sparsely punctate and pubescent; basiantennal tubercles small; interocular area with moderately deep, narrow longitudinal furrows, median area strongly convex, distinctly extending beyond the level of inner eye margins, narrow and impunctate along the median line; punctures round, smaller and sparser on median area than those near inner margins of eyes, diameter of a larger puncture as wide as medial cross section of $3^{\text {rd }}$ antennal segment, interstices between punctures with dense mesh sculpture, a little larger than half diameter of punctures. Antennae short, reaching about $1 / 2$ at base of pronotum when reflexed; $3^{\text {rd }}$ to $8^{\text {th }}$ segments much narrower than $2^{\text {nd }} ; 9^{\text {th }}$ to $11^{\text {th }}$ gradually broadened, forming a loose club; the relative length of segments from base to apex as $4.0: 3.5: 5.0: 3.0: 2.5$ : 2.0: $2.0: 1.5: 2.0: 2.5: 4.0$.

Pronotum 0.88 times as long as wide, 0.79 times as wide as elytra, widest slightly before the middle and constricted at base; disk slightly uneven, with a broad and distinct shallow median longitudinal furrow which is about $2 / 3$ times as long as pronotum, and deepest after the middle; punctures about as large as those on lateral portions of frons, interstices on actual middle larger than half diameter of punctures, distinctly smaller on lateral areas.

Elytra 0.61 times as long as wide, distinctly constricted at base, lateral margins gently divergent posteriad; posterior conjoint margins roundly and shallowly emarginated at the middle; a distinct longitudinal impression in lateral half; punctures round to elliptic, slightly rugose, same size to those on the pronotum, interstices smaller than half diameter of punctures.

Abdomen broad and subcylindrical; para- tergites moderately broad and slightly directed upwards, those of tergite 4 as broad as metatibae at apex, densely punctate; no membranous fringe at apical margin of tergite 7; punctures round, very small and sparse except for those on the base of each tergite, interstices larger than diameter of punctures.

Legs relatively short, hind tarsi 0.72 times as long as hind tibiae, $4^{\text {th }}$ tarsomeres simple.

Male. Unknown.

Female. $8^{\text {th }}$ sternite with posterior margin acutely pointed at middle; spermatheca sclerotized as in Fig. 3 d, with a broad triangular infundibulum.

Distribution. China (Shaanxi Prov.).

Remarks. This new species resembles some mountainous species of the Himalayas (brahmanus-group); from all Chinese Hemistenus, it may be distinguished by the combination of the following points: 1 . body very small in size; 2 . elytra much shorter than wide (0.61 times); 3 . interstices between punctures with dense mesh sculpture.

Etymology. The specific name is derived from the Latin word "fortunatus" means lucky.

\subsection{Stenus (Hemistenus) taibaishanus, Tang \& Puthz sp. n. (Figs. 1 d, 4 a-d)}

Type specimens. Holotype: male, Taibaishan Nature Reserve, Shaanxi Prov., alt. 2,350-2,750 m, 14.VII.2004, J.-Y. Hu and L. Tang leg. Paratype: 12 males, 12 females, same data as for the holotype; 1 male, Taibaishan Nature Reserve, Shaanxi Prov., alt. 2,750-3,300 m, 12.VII.2004, J.-Y. Hu and L. Tang leg; 11 males, 11 females, China: Shaanxi Prov., Mei County, Taibai-Shan, Xiabansi, $33^{\circ} 48.963^{\prime} \mathrm{N}, 107^{\circ} 44.483^{\prime} \mathrm{E}$, alt. $2,831 \mathrm{~m}$, 23.V.2008, H. Huang and W. Xu leg.

Holotype and paratypes are deposited in the Department of Biology, Shanghai Normal University, paratypes also in coll. Puthz (Schlitz).

Description. Brachypterous, black with bronze tint, strongly shiny, very coarsely and densely punctate; pubescence distinct, recumbent. Antennae brownish, club infuscate. Maxillary palpi yellowish. Legs reddish brown, apices of femora darker. Clypeus and labrum black, densely pubescent. Paraglossae oval. 

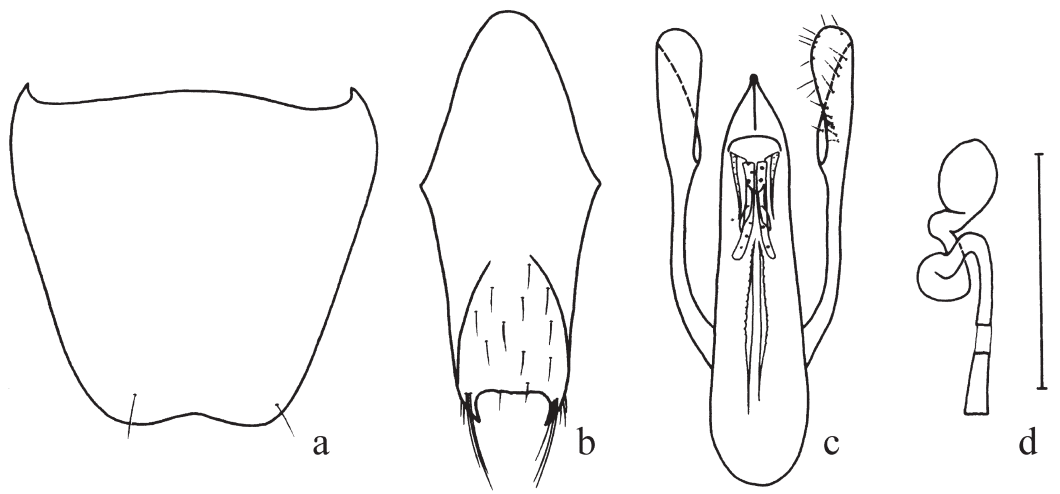

Fig. 4. Stenus (Hemistenus) taibaishanus sp. n. (a-d). - a. Male $8^{\text {th }}$ sternite. - b. Male $9^{\text {th }}$ sternite. - c. Aaedeagus in ventral view. -d. Spermatheca. Stenus (Hypostenus) nigriceps sp. n. (e-h). - e. Male $8^{\text {th }}$ sternite. - f. Male $9^{\text {th }}$ sternite. - g. Aaedeagus in ventral view. - h. Spermatheca. Scale $=0.25$ $\mathrm{mm}$.
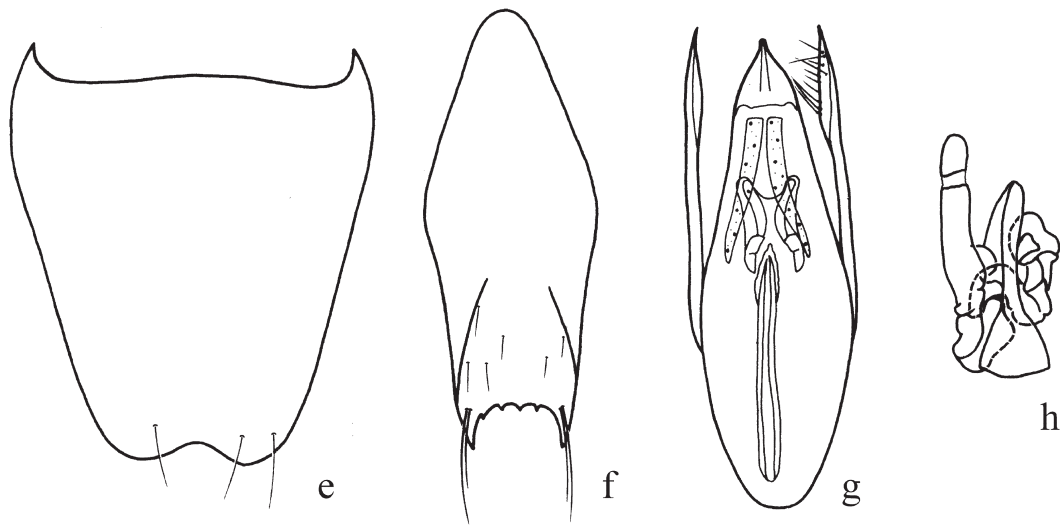

Length: 2.6-3.5 mm (forebody: $1.5-1.7 \mathrm{~mm}$ ). Head 0.96 times as wide as elytra, 1.38 times as wide as long; clypeofrontal area densely punctate and pubescent; basiantennal tubercles small; interocular area with a pair of wide and shallow longitudinal impressions, median area strongly convex, distinctly extending beyond the level of inner eye margins, broad and smooth along the median line; punctures round, almost same in size, diameter of punctures slightly larger than apical cross section of $3^{\text {rd }}$ antennal segment, interstices between punctures smooth, a little smaller than half diameter of punctures. Antennae short, reaching about $1 / 5$ at base of pronotum when reflexed; $3^{\text {rd }}$ to $8^{\text {th }}$ segments much narrower than $2^{\text {nd }} ; 9^{\text {th }}$ to $11^{\text {th }}$ gradually broadened, forming a loose club; the relative length of segments from base to apex as $3.5: 3.5: 5.5: 3.5: 3.0: 2.5: 2.5: 2.0$ : 2.5: $2.5: 3.0$.

Pronotum slightly broader than long, 0.77 times as wide as elytra, widest a little before the middle and constricted at base; disk somewhat uneven, with a faint median longitudinal furrow which is about $1 / 2$ the length of pronotum, and deepest near the middle; punctures round, mostly well delimited, partly rugose laterally, larger than those on head, about as large as medial cross section of $2^{\text {nd }}$ antennal segment, interstices smooth, a little smaller than half diameter of punctures.

Elytra 0.80 times as long as wide, distinctly constricted at base, lateral margins gently divergent posteriad; posterior conjoint margins roundly and shallowly emarginate at the middle; humeral impression shallow, a postero-lateral impression distinct; punctation slightly coarser than on pronotum, dense, in sutural half interstices can become as large as half diameter of punctures.

Abdomen cylindrical; paratergites distinct only at $3^{\text {rd }}$ segment, segments 4-6 line-like margined; posterior margin of tergite 7 with a rudimentary membranous fringe; punctures round to elliptic, gradually becoming smaller posteriad, interstices smooth, varied from smaller to larger than diameter of punctures.

Legs moderate in length, hind tarsi 0.77 times as long as hind tibiae, $4^{\text {th }}$ tarsomeres strongly bilobed.

Male. $8^{\text {th }}$ sternite (Fig. 4 a) with a shallow 
emargination at the middle of posterior margin; $9^{\text {th }}$ sternite (Fig. 4 b) with a pair of posterolateral projections which are acutely pointed apicad, posterior margin nearly straight. Aedeagus (Fig. 4 c) slender, median lobe subparallel at base and tapering apicad at about basal 6/7, apical sclerotized area with a cuspidate projection at apex and a longitudinal keel at middle, expulsion clasp small and distinctly sclerotized; parameres extending beyond apex of median lobe, broadened and folded at apex, with about 20 setae on apico-internal margins.

Female. Abdomen broader than that in male; $8^{\text {th }}$ sternite with posterior margin widely pointed at middle; sclerotized spermatheca as in Fig. $4 \mathrm{~d}$.

Distribution. China (Shaanxi Prov.).

Remarks. This new species may have affinities to the species related to $S$. evexifrons Puthz; it can be easily distinguished from other species by the combination of the following points: 1 . body black with faint bronze shine; 2 . elytra with base distinctly constricted and lateral margins gently divergent posteriad; 3. coarse punctation throughout; 4. interstices without any reticulation; 5. apical sclerotized area of aedeagus with a cuspidate projection at apex and a longitudinal keel at middle, parameres broadened and folded at apex.

Etymology. The specific name is derived from "Taibaishan", the type locality of this species.

\subsection{Stenus (Hypostenus) nigriceps, Tang \& Puthz sp. n. (Figs. 1 e, 4 e-h)}

Type specimens. Holotype: male, Taibaishan Nature Reserve, Shaanxi Prov., alt. 1,450-1,750 m, 15.VII.2004, J.-Y. Hu and L. Tang leg. Paratypes: 8 males, 2 females, same data as for the holotype; 1 female, Taibaishan Nature Reserve, Shaanxi Prov., alt. 1,750 m, 12.VII.2004, J.-Y. Hu and L. Tang leg.; 1 female, Foping Nature Reserve, Shaanxi Prov., alt. 2,065 m, 19.VII.2004, J.-Y. $\mathrm{Hu}$ and L. Tang leg.; 2 males, 3 females: above Houzhenzi, 1,300-1,700 m a.s.1., 9.VI.-3.VII. 1998, P. Jäger and J. Martens leg; 1 male, 1 female: above Houthenzi, 1,450 m a.s.1., $33.50 \mathrm{~N}$, 107.47 E, mixed deciduous forest, moss-leaves sifted, 4.VII.2001, D. Wrase leg (06b); 1 male: ibidem, mosses mushrooms sifted, 5.VII.2001,
M. Schülke leg.; 7 males, 13 females, China: Shaanxi Prov., Zhouzhi County, Houzhenzi, Qinling West Sangongli Gou, 33 $50.613^{\prime} \mathrm{N}$, $107^{\circ} 48.524^{\prime}$ E, alt. $1,336 \mathrm{~m}, 17 .-19 . V .2008, \mathrm{H}$. Huang and W. Xu leg.; 9 males, 1 female, China: Shaanxi Prov., Zhouzhi County, Houzhenzi, Qinling, 3351.203' N, 10750.183' E, alt. 1,260 m, 5.-10.V.2008, H. Huang and W. Xu leg.; 4 males, 9 females, China: Shaanxi Prov., Mei County, Taibai-Shan, Kaitianguan, $34^{\circ} 00.692^{\prime} \mathrm{N}$, $107^{\circ} 51.415^{\prime}$ E, alt. 1,883 m, 22.-23.V.2008, H. Huang and W. Xu leg.

Holotype and paratypes are deposited in the Department of Biology, Shanghai Normal University, paratypes also in the Staatliches Museum für Naturkunde, Stuttgart, in coll. Schülke (Berlin) and in coll. Puthz (Schlitz).

Description. Brachypterous, moderately shiny, head dark brown to blackish, pronotum and elytra reddish brown, abdomen darker brown, forebody moderately coarsely, densely punctate, abdomen moderately coarsely (anteriorly) to very finely (posteriorly), densely punctate; pubescence short, recumbent. Antennae light brown, club slightly infuscate. Maxillary palpi yellowish. Legs light brown. Clypeus and labrum brownish, moderately densely pubescent. Paraglossae oval.

Length: $2.7-3.2 \mathrm{~mm}$ (forebody: $1.4-1.5 \mathrm{~mm}$ ).

Head 1.08 times as wide as elytra, 1.63 times as wide as long; clypeofrontal area densely punctate and pubescent; basiantennal tubercles small; interocular area with moderately deep longitudinal impressions, median area convex, extending beyond the level of inner eye margins, narrow and smooth along the median line; punctures round, almost same in size, diameter of punctures about as large as medial cross section of $3^{\text {rd }}$ antennal segment, interstices between punctures with dense mesh sculpture, much smaller than half diameter of punctures. Antennae short, reaching about $1 / 3$ at base of pronotum when reflexed; $3^{\text {rd }}$ to $7^{\text {th }}$ segments much narrower than $2^{\text {nd }}$; $8^{\text {th }}$ to $11^{\text {th }}$ gradually broadened, forming a loose club; the relative length of segments from base to apex as 3.0: 3.0: 5.0: 3.0: 2.5: 2.0: 2.0: 1.5: 1.5: 2.0: 2.5 .

Pronotum as long as wide, 0.83 times as wide as elytra, widest a little before the middle and constricted at base; disk uneven, with a broad and 
shallow median longitudinal furrow which is about $2 / 3$ the length of pronotum, and deepest near the middle, a postero-lateral impression also present; punctures rugose, slightly confluent, same size to those on head, interstices same to those on head.

Elytra 0.88 times as long as wide, distinctly constricted at base, lateral margins gently divergent posteriad; posterior conjoint margins roundly and shallowly emarginated at the middle; punctation slightly coarser than on pronotum, slightly confluent, interstices same to those on pronotum. Hind wings degenerate.

Abdomen cylindrical; paratergites very narrow and punctate, present only in $3^{\text {rd }}$ segment, segments 4-6 line-like margined; apical margin of tergite 7 with a rudimentary membranous fringe; punctures elliptic, on tergite 3 about as on frons, very fine on tergite 7 , where the punctures are much finer than one ommatidium at inner eye margin, interstices with dense mesh sculpture, varied from smaller to larger than diameter of punctures.

Legs moderate in length, hind tarsi 0.71 times as long as hind tibiae, $4^{\text {th }}$ tarsomeres strongly bilobed.

Male. Sixth and $7^{\text {th }}$ sternite flat at posteromedian part with a slight emargination along the posterior margin of the flat; $8^{\text {th }}$ sternite (Fig. 4 e) with a shallow emargination at the middle of posterior margin; $9^{\text {th }}$ sternite (Fig. $4 \mathrm{f}$ ) with a pair of posterolateral projections which are acutely pointed apicad, posterior margin sparsely serrate. Aedeagus (Fig. 4 g) with median lobe broadest near the middle, tapering apicad, apical sclerotized area with a round projection at apex and a longitudinal keel at middle; expulsion clasp large, strongly sclerotized; parameres slender and almost straight, slightly swollen at the beginning of its apical third, which is distinctly narrowed toward apex, extending a little beyond apex of median lobe, each with 3 groups of subapical setae (4-3-3).
Female. Abdomen broader than that in male; $8^{\text {th }}$ sternite entire; sclerotized spermatheca as in Fig. $4 \mathrm{~h}$.

Distribution. China (Shaanxi Prov.).

Remarks. This new species belongs to the Stenus (Hypostenus) rufescens Sharp species group and resembles $S$. rufescens, from which it may be distinguished by the denser punctation of frons, less convex elytra (in $S$. nigriceps the elytra seem to be flattened) and the sexual characters.

Etymology. The specific name is a combination of the Latin words "nigri" and "ceps" after its black head.

Acknowledgements. We wish to express our hearty thanks to Prof. Li Li-Zhen for critical reading of the manuscript and helps in many other ways, to Dr. S.-I. Naomi for his kindness in offering his papers, to Mr Hu Jia-Yao, Mr. M. Schülke, Dr. A. Smetana, Dr. P. Jäger, Prof. J. Martens and Mr. D. Wrase who collected some of the specimens treated in this paper. The research was supported by Shanghai Normal University (No. SK200834).

\section{References}

Latreille, P. A. 1797: Précis des caractères génériques des insectes, disposés dans un ordre naturel. - Brive: F. Bourdeaux. xiv $+201+7$ pp.

Naomi, S.-I. 2006: Taxonomic revision of the genus Stenus Latreille, 1797 (Coleoptera, Staphylinidae, Steninae) of Japan: Species Group of S. indubius Sharp. — Japanese Journal of Systematic Entomology 12: 39-120.

Puthz, V. 1967: Uber Stenus (Parastenus) alpicola Fauvel und andere abweichend gebaute palaarktische Parastenus-Arten (Col., Staphylinidae). - Annales Entomologici Fennici 33(3): 226-256.

Sharp, D. S. 1874: The Staphylinidae of Japan. — Transactions of the Entomological Society of London 1874: $1-103$.

Tang, L., Li, L.-Z. \& Zhao, M.-J. 2005: Three new species of the group of Stenus cirrus (Col., Staphylinidae) from China. - Elytra, Tokyo, 33 (2): 609-616.

Zhao, C.-Y. \& Zhou, H.-Z. 2006: Three new species of the genus Stenus Latrelle (Subgenus Stenus s. str.) from China (Coleroptera, Staphylinidae, Steninae). Deutsche Entomologische Zeitschrift 53 (2): 282289. 